\title{
THE METABOLIC MEASUREMENT OF THE WATER EXCHANGE ${ }^{1}$
}

\author{
By PAUL H. LAVIETES \\ (From the Department of Internal Medicine, Yale University, and the Medical Service of the \\ New Haven Hospital, New Haven)
}

(Received for publication September 5, 1934)

Water is provided to the body in the form of obvious fluids, the water contained in solid foods, and the water produced in the oxidation of foodstuffs in the body; it is dissipated as vapor through the skin and lungs, and as liquid through the kidneys, bowel and skin. The common practice of attempting to estimate water balances by comparing the volume of the urine with the obvious fluids ingested is, therefore, quite inaccurate. The water of the food, drink, urine and feces may be determined directly. The water derived from the oxidation of foodstuffs and that lost through the skin and lungs can not be so simply measured. An indirect method for the estimation of these fractions of the water exchange has, therefore, been proposed by Newburgh (1). Estimations of water exchange by this method have yielded improbable results in many of our cases. Failure to obtain good results can not be attributed to disregard of the prescribed conditions, as will be shown below, nor is there reason to doubt the accuracy of the observations. Since this is so, a report of our experiences and a comprehensive investigation of the errors of the method seem warranted.

It has been shown earlier that the calculations of Newburgh may be simplified by the use of the following formula, derived without additional assumptions (2):

$$
\begin{array}{r}
\Delta W=\Delta \text { Body weight }+\left(S_{e}-S_{f}\right) \\
+(0.49 P+F+C)_{b} .
\end{array}
$$

Water exchange $=$ Body weight change

+ Solids lost + Food burned to

$$
\left(\mathrm{CO}_{2}+\mathrm{H}_{2} \mathrm{O}\right) \text {. }
$$

Newburgh (1) used, to check the accuracy of his determinations, a so-called "predicted water balance":

Predicted $\Delta W=\Delta$ Body weight

Predicted balance $=$ Body weight change $\frac{-(P+F}{\text {. }}$ - Foodstuffs stored.

1 Part of the expense of this investigation was defrayed by a grant from the Ella Sachs Plotz Foundation.
As the fat metabolized is estimated in the same manner for both predicted and determined balances, one can hardly serve as a check on the other in this respect. Furthermore, since "predicted balance " neglects entirely changes in the salt content of the body and in the quantity of unassimilable materials in the gastro-intestinal tract, it can equal determined balance only when the intake of salt and roughage equals the output and when no fat is lost in the stools. Actually in the experiments of Newburgh (1) the predicted balance falls short of the determined balance in every case except one. The discrepancies are in the direction which is to be expected, since " predicted balance" neglects stool fat. The greatest discrepancies occurred on days when unusually large stools were passed. This again accords with expectation, since on such days the excretion of roughage is likely to exceed the intake, causing the predicted value to fall even further below the determined value. It is evident that the "predicted balance" can not be used to verify the "determined balance."

There can be no doubt that Equation 1 represents a true expression of water exchange. It remains to evaluate the accuracy of the various measurements and assumptions involved. These are: (a) accurate measurements of the solids of ingesta and excreta; $(b)$ the assumption that protein burned can be estimated accurately from nitrogen excretion; $(c)$ the assumption that carbohydrate fed is identical with carbohydrate burned; (d) accurate measurements of the foodstuffs fed; (e) a method for the determination of total metabolism, from which fat metabolized can be estimated.

(a) The determination of the solids of ingesta and excreta is not an extremely accurate procedure. So great are the difficulties in drying such materials completely without loss by volatilization or decomposition that accuracy greater than \pm 5 per cent should not be expected. Since the total 
solids of urine and feces are only about $\mathbf{5 0}$ grams daily, errors on the excretory side of the balance would be negligible. The solids of the ordinary diet for adults, however, are of the magnitude of 500 grams daily, and errors in this measurement are quite significant. To obtain the weight of food solids, Newburgh (1) dried entire mixed diets, in metal containers, on the steam bath at $70^{\circ} \mathrm{C}$. for about three weeks. In one experiment (recorded in Table 9 of the appendix of his report), duplicate diets, in which the total weight of protein, fat and carbohydrate was estimated at 197.5 grams, were so treated for 25 successive days. The extreme values for determined dry weight were 179 grams and 223 grams per day. The average value, 198 grams, allowed for the presence of no salts or unassimilable material. In our experiments food was dried by a different method which proved no more satisfactory. The entire diet was weighed, passed through a meat grinder and mixed in a large container for one hour with a mechanical stirrer. Aliquots of varying weights, in porcelain evaporating dishes, were kept on the steam bath for about 12 hours, in the oven at $95^{\circ} \mathrm{C}$. for about 1 hour, and in a desiccator over sulphuric acid until constant weight was reached. Solids so determined frequently fell short of the estimated weight of protein, fat and carbohydrate in the diets, although analyses of samples taken from the top and bottom of the wet mixtures differed by no more than \pm 1 per cent in nitrogen and chloride. Furthermore variations as great as 10 per cent were noted in the determined dry weights of identical diets prepared on different occasions. Newburgh feels that greater accuracy is possible when simple diets are used. The data recorded in the first table of the appendix of his first report (1) do not support this statement. The determined solids of bread are seen to vary from 57.5 to 66.2 per cent; those of milk from 14.2 to 15.5 per cent. These variations are in the neighborhood of 10 per cent. As water exchange is obtained by subtracting from the change of body weight that portion of the ingested solids which is neither excreted nor burned, any incompatibility between determined solids and estimated foodstuffs must introduce an error in the calculation of water exchange.

(b) The assumption that protein metabolized can be accurately estimated from nitrogen excre- tion. Over long periods there can be little error in assuming that the nitrogenous end-products of protein metabolism are excreted as soon as they are formed. In short periods this need not be so. This is particularly true when large changes occur in the concentration of urea in the body fluids. In such cases, if the concentrations of urea in the body fluids at the beginning and end of an experiment are known, however, some attempt at correction may be made. Nitrogen excreted as protein in the urine or stool must, of course, be excluded from the calculation since protein excreted as such gives rise to no water and is included in the dry weights of the ingesta and excreta.

(c) An assumed value for carbohydrate burned. In prolonged experiments under constant conditions it is assumed, with justification, that carbohydrate fed equals carbohydrate burned. In short experiments, especially in subjects with nutritional disturbances, however, such an assumption is certainly unwarranted and carbohydrate burned can be estimated by no method short of calorimetry. In many conditions in which the analysis of large water exchanges is important, for example in diabetic acidosis or pyloric obstruction, the method of determination falls completely short in this respect.

(d) For the measurements of the food mixture ingested dependence must be placed for the most part upon standard dietary tables and certain factors. These tables at best provide only average values, and one has but to glance at them to recognize the extreme variability of common articles of food. Much of this variability probably depends upon the exposure and desiccation to which the foods have been subjected. In the tables of Atwater and Bryant for example (3) the carbohydrate content of raw potato is given as 18.4 per cent, the average of 136 analyses ranging from 13.5 to 27.4 per cent. In certain foods the variability of fat is quite as great. Protein can be directly measured by determination of nitrogen and, while the factor, 6.25 , used to convert nitrogen to protein, is not universally applicable, the error involved in its wholesale use is probably relatively unimportant. ${ }^{2}$ It must not be over-

2 It should be mentioned that in this laboratory the nitrogen of mixed diets has been found higher than the predictions of standard tables in most instances. This may be because the foods have not been dried before 
looked that factors for the caloric value of all foodstuffs are subject to similar errors. Direct analysis may be employed to obviate these errors and is reasonably satisfactory for extremely simple diets. In many instances, in studies of diseased subjects, however, such diets are unsuitable for application over long periods of time because the patients' tastes must be given some consideration. Analysis of mixed diets is a difficult procedure. Total caloric content determined by bomb calorimetry must be corrected for cellulose content. Furthermore the possibility of significant variations from day to day can not be excluded without frequent analyses.

(e) Estimation of energy expenditure from insensible perspiration. Soderstrom and DuBois (4) reported 175 experiments in which total heat production and water of vaporization were determined simultaneously in the Russell-Sage calorimeter on both normal and diseased subjects under carefully standardized conditions. In 27 experiments on 12 normal men, an average of 24 per cent of the total heat produced was expended in the vaporization of water, with extremes of 21 and 28 per cent. ${ }^{3}$ When the heat production was increased 10 to 15 per cent by the administration of glucose or protein, water of vaporization increased proportionally. The variability was larger in disease and, in certain conditions, characteristic deviations were observed. In a group of cretins the water loss was small in comparison with the heat production. In patients with heart disease and dyspnea it was abnormally large. This the authors ascribed to increased losses through respiration. In nephritics with dyspnea, however, the loss by vaporization was normal. In typhoid fever, as long as the body temperature remained constant, regardless of its actual level, the normal relation between heat production and water loss was maintained. While the temperature was rising vaporization was deficient; while it was falling there was excessive vaporization. These figures lend strong

analysis and therefore all volatilization of nitrogen has been avoided. That the analyses are correct is attested by recovery experiments and by the fact that nitrogen equilibrium has been secured in prolonged experiments on normal subjects receiving adequate diets.

${ }^{3}$ In one of 2 women studied the deviation from the average was even larger. support to the general theory that the quantities of water vaporized from the skin and lungs are closely related to the total heat elimination and, therefore, when the body temperature remains constant, to heat production. Nevertheless, it must be recognized that the degree of variability in this relationship amounted to from -12 to +15 per cent even in normal males.

Levine and Wilson (5) in 53 similar experiments with infants found that vaporization of water accounted on the average for 26 per cent of the heat production, with deviations seldom exceeding \pm 10 per cent of the average. Heller and Schwarz (6) have subjected to statistical analysis all the data in the literature from direct calorimetry experiments in which total heat production and water loss have been measured directly. In about 850 experiments, conducted under basal conditions, in which heat production varied from 900 to 2200 calories per day, the proportion of heat eliminated by vaporization approximated closely the average value of 24 per cent found by Soderstrom and DuBois. Above 2200 calories the percentage lost by vaporization was somewhat smaller. From a similar analysis of 400 experiments in which subjects took food but abstained from exercise, Heller and Schwarz concluded that the same relationship obtained when the total heat production varied between 1200 and 2600 calories. Above this the proportion of heat lost by vaporization fell off, just as it had above 2200 calories under basal conditions. This loss of correlation at high levels of heat production may be referable merely to technical errors, failure of the ventilating systems of the calorimeters to prevent the relative humidity of the atmosphere from rising when vapor production was great. This would lead to absorption by the calorimeter and its furnishings of water which would consequently escape measurement.

Benedict and Root (7), in short periods of study under controlled basal conditions, found a relationship between heat production, measured by indirect calorimetry, and insensible perspiration or loss of weight which is defined by the following linear equation :

$$
\text { Calories }=1.325 I L+19.3 \text { per hour, }
$$

in which $I L$ represents the insensible weight loss per hour. Jores (8), Heller (9) and others have 
confirmed the essential validity of the Benedict and Root equation when applied to subjects under basal conditions.

If 24 per cent of the total heat produced is eliminated by vaporization of water with a heat equivalent of 0.58 calories per gram,

$$
\text { Calories }=0.58 \mathrm{IW} / 0.24=2.42 \mathrm{IW},
$$

$I W=$ Water of vaporization or " insensible water." Furthermore, since the only difference between insensible weight loss and insensible water is referable to exchange of gases, $I L=I W+$ $\left(\mathrm{CO}_{2}-\mathrm{O}_{2}\right)$. Under basal conditions the respiratory quotient must be approximately constant, and consequently $\left(\mathrm{CO}_{2}-\mathrm{O}_{2}\right)$ and therefore $I L$ must be proportional to heat production. At an average basal respiratory quotient $\left(\mathrm{CO}_{2}-\mathrm{O}_{2}\right)$ is approximately $0.1 I \mathrm{~W}$. Therefore $I L=1.1 \mathrm{IW}$ or

$$
I W=0.91 I L \text {. }
$$

Substituting this value in Equation 4

$$
\text { Calories }=(0.91 \times 2.42) I L=2.2 I L \text {. }
$$

The curve defined by this equation passes through the origin and deviates considerably from that of Benedict and Root. ${ }^{4}$ Since the curve of Benedict and Root is evidently incompatible with the relationship between water vaporized and heat production established by calorimetry experiments, it becomes necessary to explain the fact that it conforms with reasonable accuracy to their own data and those of other workers. The curve of Equation 3 crosses that of Equation 5 at a value of 48.5 calories per hour and predictions of metabolism from $I L$ by Equation 3 do not diverge more than 10 per cent from those by Equation 5 within the limits 66 and 36 calories per hour. Since these include the variations ordinarily encountered in basal determinations in adults, agreement within 10 per cent with the Benedict and Root curve does not prove that this curve is correct. It is hard to escape the conviction that the peculiar course taken by this curve is referable to fortuitous circumstances connected with the limited conditions under which the experiments of Benedict and Root were conducted.

4 The equation conforms closely to that derived by Levine and Marples (10) from their own data and those of Soderstrom and DuBois, Calories $=2.27 I L-1.25$ per hour.
Johnston and Newburgh (11) used the insensible weight loss as a measure, over long periods of time, of the total metabolism of hospitalized patients who were allowed limited activity. Subsequently Newburgh, Wiley and Lashmet (12), desiring to extend the study to subjects of more varied types under different circumstances of life, abandoned the equation of Benedict and Root, substituting a method of calculation which related heat production directly to insensible water loss. They measured, for periods of 5 to 85 days, the daily insensible weight losses of 8 subjects who were given diets aimed to maintain them as nearly as possible in a constant state of nutrition while they pursued their ordinary activities. This provided data for the estimation of the mixture of foodstuffs burned, the total energy production and the insensible water loss. All the individuals but one eliminated as heat of vaporization 23.8 to 25.2 per cent of the estimated energy production, which varied from 2075 to 3650 calories per day. In the one exception frequent unavoidable labor caused considerable sensible perspiration. To calculate the insensible water loss from the insensible weight loss under varying conditions, they employed a method of approximation. A formula for the direct estimation of fat burned from the determined insensible weight loss, protein burned, and carbohydrate burned, without the use of this series of approximations can be obtained as follows:

(a) $I L=I W+\left(\mathrm{CO}_{2}-\mathrm{O}_{2}\right)$, $I W \times 0.58=$ cal. $\times 0.24$,

(b) $I W=0.414$ cal.,

(c) $\left(\mathrm{CO}_{2}-\mathrm{O}_{2}\right)=$ $(0.42 C+0.14 P-0.07 F)$ burned,

(d) $\mathrm{Cal}=(4.1 P+4.1 C+9.3 F)$ burned. (a)

Substituting $(d)$ in $(b)$, and $(b)$ and $(c)$ in

(e) $I L=(2.12 C+1.69 P+3.78 F)$ burned. Solving for $F_{b}$ :

$$
F_{b}=\frac{I L-2.12 C_{b}-1.69 P_{b}}{3.78}
$$

This equation has been accepted by Newburgh (13) as a valid condensation and accurate representation of the calculations involved in his method of approximations. 
Newburgh, Wiley and Lashmet (12) state that the amount of energy expended in external work in ordinary activities is negligible, becoming significant only when heavy labor is performed. In this case the difference between energy transformations and heat production will become evident only during heavy muscular exercise and heat production can therefore be used as a practical measure of energy production under ordinary circumstances. The technical difficulties encountered in measuring separately heat production and energy expenditure during work have proved so great that the point at which the difference between the two becomes significant has not yet been ascertained. It is hardly to be doubted that there machine, some effective work must be performed. It has been shown in these experiments, and even more clearly in later experiments of Benedict and Carpenter (15), that, although in the resting subject approximately 23 per cent of the heat eliminated goes into the vaporization of water, with increasing amounts of work the percentage rises far above this level. The data of these experiments are presented in Table I. In some, shown in Table II, it is possible to compare water losses directly measured against insensible weight losses. The agreement is good. It seems clear from these experiments that even during moderate work there may be a significant difference between total energy transformation and heat production

TABLE I

Relationship of heat of vaporization to heat production and to total energy transformation during varying activity for 24 hour periods. (From Benedict and Carpenter)

\begin{tabular}{|c|c|c|c|c|c|c|c|c|c|c|c|c|c|c|}
\hline \multirow{3}{*}{ Subject } & \multicolumn{2}{|c|}{$\frac{\text { Rest }}{\begin{array}{c}\text { Heat } \\
\text { production }\end{array}}$} & \multicolumn{2}{|c|}{$\begin{array}{c}\text { Heat } \\
\text { production }\end{array}$} & \multicolumn{2}{|c|}{$\underset{\text { production }}{\text { Energy }}$} & \multicolumn{2}{|c|}{$\begin{array}{c}\text { Heat } \\
\text { production }\end{array}$} & \multicolumn{2}{|c|}{$\begin{array}{c}\text { Energy } \\
\text { production }\end{array}$} & \multicolumn{2}{|c|}{$\begin{array}{c}\text { Heat } \\
\text { production }\end{array}$} & \multicolumn{2}{|c|}{$\underset{\text { production }}{\text { Energy }}$} \\
\hline & \multirow{2}{*}{ Total } & Vapor & \multirow{2}{*}{ Total } & Vapor & \multirow{2}{*}{ Total } & Vapor & \multirow{2}{*}{ Total } & Vapor & \multirow{2}{*}{ Total } & Vapor & \multirow{2}{*}{ Total } & Vapor & \multirow{2}{*}{ Total } & Vapor \\
\hline & & Total & & Total & & Total & & Total & & Total & & Total & & Total \\
\hline $\begin{array}{l}\text { E. O... } \\
\text { J. F. S. } \\
\text { J. C. W. } \\
\text { B. F. D. } \\
\text { A. L. L.. }\end{array}$ & $\begin{array}{l}2283 \\
2133 \\
2397 \\
2213 \\
2304\end{array}$ & $\begin{array}{l}24.7 \\
22.9 \\
21.8 \\
25.7 \\
24.3\end{array}$ & $\begin{array}{l}3662 \\
3344\end{array}$ & $\begin{array}{l}35.9 \\
29.4\end{array}$ & $\begin{array}{l}3862 \\
3544\end{array}$ & $\begin{array}{l}34.0 \\
27.8\end{array}$ & $\begin{array}{l}4577 \\
4145 \\
4270\end{array}$ & $\begin{array}{l}42.8 \\
40.6 \\
48.6\end{array}$ & $\begin{array}{l}5147 \\
4565 \\
4727\end{array}$ & $\begin{array}{l}38.0 \\
36.8 \\
44.0\end{array}$ & $\begin{array}{l}7832 \\
6180\end{array}$ & $\begin{array}{l}55.3 \\
56.4\end{array}$ & $\begin{array}{l}9314 \\
7137\end{array}$ & $\begin{array}{l}46.4 \\
48.8\end{array}$ \\
\hline
\end{tabular}

is such a point and that it requires more exact definition than the terms " heavy labor" or " vigorous muscular exercise." Atwater and Benedict (14) measured total energy transformation by direct calorimetry, and external work by means of a bicycle ergometer, in a group of normal subjects who worked for 8 hours daily on the bicycle. The work is described as reasonable and not at all excessive. In these experiments the average energy transformation exceeded heat production by about 500 calories which was almost the exact heat equivalent of the measured external work. The total energy expenditure was approximately , 5000 calories. The measured external work was equivalent to approximately 200,000 kilogrammeters. Moderately active normal subjects may well transform 4000 calories daily, in which case, unless the human body is an extremely inefficient and that with increasing amounts of work the portion of the total heat eliminated by vaporization increases considerably. It is possible that in Newburgh's experiments exercise was even more moderate and that a slighter increase in the percentage of heat lost by vaporization was balanced by a slight discrepancy between heat production and total energy transformation so that water of vaporization bore the same ratio to total energy production under the circumstances of his experiments that it usually bears to heat production during rest. It is, however; impossible to define the level of activity at which these two processes will neutralize one another. Heller and Schwarz (6), from their analyses of work experiments, conclude that when the heat production exceeds 3000 calories daily the process of vaporization assumes a larger share of the load of heat 
dissipation. No distinction is made, in these work experiments, between vaporization from sensible or insensible perspiration. The performance of such amounts of work under ordinary circumstances must entail some sweating. It is important to note that sweat which falls from the body or is absorbed by clothes and bedding, thus escaping vaporization on the surface of the body, has no appreciable value in heat elimination. This factor is minimized in the calorimeter experiments cited, by direct measurement of water vaporized. It is impossible to say, however, that some of this was not vaporized from the floor or furnishings of the calorimeter rather than from the skin, in which case the values for heat elimination by vaporization from the body will be too high.

TABLE II

Comparisons of insensible water loss (IW) measured directly with insensible weight loss (IL) derived from measurements of body weight changes corrected for weight of ingesta and excreta, during work experiments of Benedict and Carpenter.

\begin{tabular}{|c|c|c|}
\hline Experiment & $\begin{array}{c}\text { IW } \\
\text { grams } \\
\text { per } 24 \\
\text { hours }\end{array}$ & $\begin{array}{c}I L \\
\text { grams } \\
\text { per } 24 \\
\text { hours }\end{array}$ \\
\hline $\begin{array}{ll}56 & \cdots \\
57 & \cdots \\
62 & \cdots \\
63 & \cdots \\
64 & \cdots\end{array}$ & 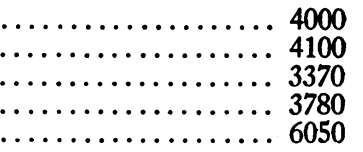 & $\begin{array}{l}4260 \\
4600 \\
3640 \\
3920 \\
6640\end{array}$ \\
\hline
\end{tabular}

If the mean temperature of the body is to remain constant, heat production must equal heat elimination. Heat elimination is effected through radiation and vaporization from the respiratory passages and body surface. In the lungs the process of radiation consists of raising the temperature of the inspired air toward the temperature of the body. The amount of heat lost in vaporization should depend on the osmotic pressure ${ }^{5}$ of the body fluids and the quantity of water

5 It might seem, at first sight, that the heat value of the vaporization of hypotonic sweat would differ from that of the isotonic fluid from which the sweat was derived. However, a certain exchange of heat must have attended the separation of hypotonic sweat from isotonic body fluids. If the sweat emanates from these fluids the heat of secretion plus the heat of vaporization must exactly equal the heat that would be required to vaporize the original isotonic fluid directly, because the energy expended in any chemical or physical transformation is the same, regardless of the methods or intermediate processes by which it is achieved. vaporized. Christie and Loomis (16) have shown that the expired alveolar air is almost, but not completely, saturated with water vapor at the temperature of the body, that it is more nearly saturated after a period of apnea, less during hyperventilation, and that the vapor pressure of the air in the respiratory dead space is much less than that in the alveolar air. Consequently less water is vaporized by shallow respirations than by deep ones. All these factors which determine the amount of water vapor eliminated by the respiratory system presumably have a similar influence upon the heat lost by radiation and upon the respiratory gas exchange. Therefore both the total amount of heat eliminated by the lungs and the fraction referable to vaporization may be expected, on theoretical grounds, to parallel energy production. Benedict and Benedict (17) have shown that under basal conditions approximately 40 per cent of the total water vaporized comes from the respiratory passages.

In the skin the situation is more complex. If water is lost by evaporation from the surface of the body without appreciable quantities of solute, as insensible perspiration, the external layers of the skin must have a vapor tension. The water given off as vapor from these layers to the surrounding air is presumably renewed by diffusion as the osmotic pressure at the surface is increased by the concentrating effect of evaporation. The fluid vaporized in this manner should depend on the surface area of the body and the gradients of temperature and humidity between the surface and the surrounding air.

The quantities of heat lost both by radiation and by vaporization then should be related to heat production, if this is equal to heat elimination, and to the size or surface area of the subject. It is impossible to say, on theoretical grounds, that the effects of surface area and heat production upon radiation and vaporization will be proportional. If mean body temperature is to remain constant, under fixed environmental conditions, radiation and vaporization must be automatically controlled in accordance with total heat production. The temperature of the skin (and possibly of the respiratory passages) must vary with the heat production through the intermediation of the peripheral circulation. Conversely, when the environmental temperature changes, there must be a cor- 
responding circulatory adjustment to maintain a relatively constant gradient of temperature between the body surface and the environment. Such adjustments have been demonstrated repeatedly as has also the existence of a temperature gradient between the body surface and the deeper tissues (18).

Apparently, when heat production exceeds a certain maximum or when the gradient of temperature between the environment and the body surface becomes too small, some process of heat elimination more active than the insensible perspiration is required. In the dog, which is unable to sweat, radiation and vaporization through the respiratory passages are increased by panting. In humans the respiratory elimination of heat seems to follow the dictates of oxygen requirements, responding to the temperature control only when heat dissipation by the skin is prevented, for example in hot baths. Instead the sweat glands are called into play to provide a larger volume of fluid for vaporization. There is no special reason for believing, however, that radiation of heat by either lungs or skin must be influenced by the process of sweating. If it is not, the proportion of the total heat loss which is referable to vaporization should increase steadily with the amount of sweat evaporated. That this increase actually occurs during work has already been shown.

Water loss from the skin may occur with or without the intermediation of the sweat glands. Furthermore, it is possible that moderate activity of the sweat glands need not give rise to sensible perspiration. Yet the intervention of the secretory mechanism, even when it is not marked enough to produce sensible perspiration, will presumably increase the proportion of heat dissipated by vaporization. Sweat secretion without sensible perspiration may account for the increase in vaporization noted by Newburgh when a subject experiences a feeling of uncomfortable warmth. That large amounts of water may be vaporized from the skin without the intermediation of the sweat glands has been adequately demonstrated. In subjects with congenital absence of the sweat glands the percentage of heat lost by vaporization is normal unless the metabolism is greatly increased by work, in which case the rise in vaporization is deficient $(19,20)$. From the washings of the skin of a normal subject who had remained unbathed for one week during which he experienced no sweating nor sensation of uncomfortable warmth, no appreciable amount of $\mathrm{Cl}$ was recovered, indicating that the large amount of water vaporized during the week was supplied without the aid of the sweat glands (21). Vasti (22), by an ingenious method for the detection of activity of the sweat glands over small areas, found evidence of activity in only 5 normal subjects at rest, and in these cases the water losses from the same areas were 18 to 72 per cent higher than those observed in the remainder of the subjects. No note is made concerning the presence or absence of sensible sweating in these experiments, although presumably it did not occur. Vasti noted also that in other experiments when the environmental relative humidity was increased without change of environmental temperature vaporization decreased until the relative humidity approached 80 per cent, when it began to increase. At this point the subjects experienced a sensation of uncomfortable warmth. If this sensation of uncomfortable warmth is an indication of sweat gland activity, it may be that the exclusion of experiments in which this occurs, which has been recommended by Newburgh, may eliminate the factor of activity of the sweat glands. Even so, this requirement imposes a marked restriction upon experiments conducted on non-resting subjects since sweating can apparently be induced under certain conditions by changes of humidity as well as environmental temperature. Activity of the sweat glands at high environmental humidity might serve to facilitate evaporation by supplying a solution on the skin surface which has a higher vapor pressure than that of the isotonic fluid of the epidermis.

It is probably true that for normal subjects and with some exceptions for diseased subjects a fairly constant proportion of the heat production is eliminated through the process of vaporization of water under conditions of rest or of slight activity such as dressing and undressing, standing, and walking about the calorimeter, whether or not food is taken, when conditions of temperature and humidity are reasonably constant. It has been noted that the individual variability is of the order of \pm 10 per cent, however, and that certain individuals tend to vary constantly in one direction from the mean. Furthermore when the me- 
tabolism is increased by the performance of work, a greater proportion of the heat produced is dissipated by vaporization. It is possible that this occurs only when sweat secretion is called into play.

Heat loss by vaporization bears a fairly constant relationship to total heat elimination during changes of body temperature $(23,24,25,26)$ but heat elimination falls short of heat production during increases of temperature and exceeds heat production when the temperature falls. Therefore, while vaporization parallels heat elimination, it becomes totally unrelated to heat production under these circumstances. If the specific heat of the body is assumed to be 0.83 , for a subject of $60 \mathrm{kgm}$. an increase in body temperature of $1^{\circ}$ C. will require that heat production exceed heat elimination by $60 \times 0.83=50$ calories. For studies of 24 hours or more such changes have relatively little significance. For studies over shorter periods, changes of $0.5^{\circ} \mathrm{C}$., which may occur even physiologically are significant. With greater changes in body temperature, such as occur in disease, the significance is much greater. For example, during a malarial chill, Barr and DuBois (24) found that the heat production of subject George S. was $153.1 \mathrm{Cal}$. in 40 minutes while the heat elimination was only $53.7 \mathrm{Cal}$., the difference serving to raise the rectal temperature $2^{\circ} \mathrm{C}$. During this period, $16.7 \mathrm{Cal}$. were dissipated by vaporization. This is approximately 31 per cent of the total heat eliminated, but only 11 per cent of the heat produced. Temperature changes of considerable magnitude are frequently encountered in disturbances of metabolism without infection, for example, in recovery from diabetic acidosis, during which determinations of insensible losses and water balances have been attempted in this Department. It is apparent that if vaporization is to be used as a measure of heat production in such cases, a correction must be made for change in body temperature. It is also conceivable that in such cases a considerable amount of the heat produced is used to warm the large amounts of fluids administered, so that heat elimination falls even further short of heat production. It would require, for example, 48 calories to raise the temperature of 3 liters of fluid given at $20^{\circ} \mathrm{C}$. to the temperature of the body. This might be quite significant in short periods of study.
During the sleeping hours vaporization is greater in proportion to heat production than it is during the waking hours. Thus Benedict and Carpenter (15) found that during the 6 hours from 1 a.m. to 7 a.m., 17 subjects eliminated by vaporization 27 per cent of the total heat produced, while during the waking hours the average for the same subjects was 21 per cent. For 24 hours the average was 23 per cent. The usual fall in body temperature of $0.5^{\circ} \mathrm{C}$. during the night and comparable rise during the waking hours could account for the higher percentage of heat eliminated by vaporization during the night. In any event it would be absurd to use the same factor to convert water of vaporization to total heat production in short experiments conducted during the day and during the night.

Unreasonably large variations in the relationship of insensible water to heat production have been frequently encountered in experiments of our own conducted even over long periods. Data from some of these are presented in Table III. The methods employed in these experiments are comparable in accuracy to those of Newburgh. Body weight was determined on a silk balance capable of measuring within \pm 5 grams. The weights of diets measured in the diet kitchen agreed closely with those of duplicate diets weighed in the laboratory. Stools were sent immediately to the laboratory for weighing. Urine was saved at the bedside until the end of a 24 hour period, when it was removed and weighed by the author. The first 4 cases are patients with nephritis, the fifth a patient with diabetes insipidus. In all of these, extremely large variations in the volume of fluids in the body occurred during the course of study. The subjects were asymptomatic and confined to bed at all times. The room temperature was kept at about $20^{\circ} \mathrm{C}$. No sensible perspiration or uncomfortable warmth was noted. The experimental diets were used for at least 3 days previous to the beginning of our observations. In spite of this the insensible loss is seen to vary widely during individual periods in each case. Since all the precautions prescribed for the use of the method were observed, these experiments can not be excluded merely because they fail to fulfill expectations.

The last experiment was conducted upon the 
TABLE III

Insensible weight loss (Author's experiments)

\begin{tabular}{|c|c|c|c|c|c|c|}
\hline Subject & $\underset{\text { tion }}{\text { Dura- }}$ & Diet & $I L$ & $\begin{array}{c}\text { Body } \\
\text { weight }\end{array}$ & $\underset{\text { of serum }}{\mathrm{Na}+\mathrm{K}}$ & $I L \times 2.2$ \\
\hline & days & $\begin{array}{c}\text { calories } \\
\text { per } 24 \\
\text { hours }\end{array}$ & $\begin{array}{l}\text { grams } \\
\text { per 24 } \\
\text { hours }\end{array}$ & kgm. & m.Eq. & $\begin{array}{l}\text { calories } \\
\text { per } 24 \\
\text { hours }\end{array}$ \\
\hline J. McC. & $\begin{array}{l}2 \\
2 \\
2 \\
2\end{array}$ & $\begin{array}{l}2630 \\
2564 \\
2595 \\
2568\end{array}$ & $\begin{array}{l}1702 \\
1250 \\
1742 \\
1554\end{array}$ & $\begin{array}{l}67.55 \\
67.69 \\
67.34 \\
67.80 \\
68.04\end{array}$ & & $\begin{array}{l}3745 \\
2750 \\
3832 \\
3420\end{array}$ \\
\hline D. C... & $\begin{array}{l}2 \\
2 \\
2 \\
2 \\
2\end{array}$ & $\begin{array}{l}2455 \\
2488 \\
2461 \\
2464 \\
2511\end{array}$ & $\begin{array}{l}1832 \\
1524 \\
1019 \\
1717 \\
1420\end{array}$ & $\begin{array}{l}63.42 \\
64.74 \\
64.88 \\
64.96 \\
64.99 \\
65.23\end{array}$ & & $\begin{array}{l}4031 \\
3352 \\
2241 \\
3780 \\
3122\end{array}$ \\
\hline P. F... & $\begin{array}{l}2 \\
2 \\
2 \\
2 \\
2\end{array}$ & $\begin{array}{l}2697 \\
2671 \\
2673 \\
2791 \\
2724\end{array}$ & $\begin{array}{l}1215 \\
1386 \\
1224 \\
1667 \\
1632\end{array}$ & $\begin{array}{l}62.33 \\
61.66 \\
61.38 \\
61.31 \\
60.11 \\
59.64\end{array}$ & & $\begin{array}{l}2673 \\
3050 \\
2692 \\
3670 \\
3591\end{array}$ \\
\hline J. M... & $\begin{array}{l}2 \\
2 \\
2 \\
2\end{array}$ & $\begin{array}{l}2531 \\
2528 \\
2508 \\
2450\end{array}$ & $\begin{array}{l}1101 \\
1019 \\
1310 \\
1134\end{array}$ & $\begin{array}{l}49.50 \\
49.99 \\
51.10 \\
52.10 \\
54.41\end{array}$ & $\begin{array}{l}131 \\
125 \\
134\end{array}$ & $\begin{array}{l}2421 \\
2241 \\
2881 \\
2495\end{array}$ \\
\hline M. C... & $\begin{array}{l}2 \\
2 \\
2 \\
1 \\
1 \\
1\end{array}$ & $\begin{array}{l}2024 \\
2145 \\
2120 \\
2260 \\
2220 \\
2060\end{array}$ & $\begin{array}{r}840 \\
1112 \\
1190 \\
1069 \\
1664 \\
851\end{array}$ & $\begin{array}{l}73.46 \\
74.54 \\
76.30 \\
74.15 \\
74.25 \\
77.44 \\
74.60\end{array}$ & $\begin{array}{l}152 \\
144 \\
135 \\
145 \\
147 \\
138 \\
145\end{array}$ & $\begin{array}{l}1848 \\
2446 \\
2620 \\
2351 \\
3660 \\
1872\end{array}$ \\
\hline P. L. . & $\begin{array}{l}2 \\
2 \\
2 \\
2 \\
2 \\
2 \\
2 \\
2 \\
2 \\
2\end{array}$ & 3090 & $\begin{array}{l}1558 \\
1419 \\
1477 \\
1333 \\
1437 \\
1265 \\
1507 \\
1646 \\
1529 \\
1470\end{array}$ & $\begin{array}{l}74.72 \\
74.64 \\
74.92 \\
74.92 \\
74.36 \\
74.09 \\
74.43 \\
74.60 \\
74.65 \\
74.63 \\
74.40\end{array}$ & & $\begin{array}{l}3430 \\
3120 \\
3250 \\
2935 \\
3161 \\
2785 \\
3317 \\
3621 \\
3365 \\
3235\end{array}$ \\
\hline
\end{tabular}

author who pursued his ordinary activities during the twenty days of the study. During the fourth, fifth and sixth periods he took 40 grams of urea daily, producing a slight water loss as indicated by change of body weight. There were no symptoms referable to the urea ingestion. During these urea periods the average daily insensible loss was far below that of the other days; in fact it was lower than the smallest loss noted on any other day. There is no reason to believe that the urea decreased the energy metabolism to a comparable extent. Certainly in these experiments any prediction of total metabolism from insensible loss must be erroneous even for 24 or 48 hour periods. Some factor must be present which causes the relation of vaporization to heat production to vary widely from the accepted value.

Much evidence has accumulated to show that changes in the volume of fluid in the body have a profound effect on the proportion of heat lost by vaporization. Manchester, Husted and McQuarrie (27) found that insensible weight loss increased when excessive amounts of fluid were stored under the influence of pituitrin, and decreased during dehydration produced by fluid restriction and ketogenic diets. Newburgh and Johnston (28) have suggested that these results are referable to the fact that the calculations were based on insensible weight losses and not on insensible water losses, and have presented evidence to show that vaporization is uninfluenced by changes in body water of as much as 6 per cent. Levine, Wilson and Kelly (29) were unable to demonstrate that ordinary variations of fluid intake affected the insensible water losses of infants. In dehydrated infants, however, Levine and $\mathrm{Wy}$ att (30) found that insensible losses were distinctly reduced, returning to normal after the volume of fluids in the body had been restored. Jores (31) has found that the insensible loss is abnormally small in states of dehydration and may vary during diuresis or the accumulation of edema. Robert (32) noted striking increases of insensible perspiration when the volume of fluid in his normal subject was expanded under the influence of pituitrin and fluid administration. In our own experiments, although unusually large changes in insensible loss were associated with large changes of the volume of fluid in the body, no correlation between the two could be detected.

The discovery by Gilman and Barbour (33) that insensible water losses are related to the osmotic pressure rather than to the volume of body fluids offers an attractive but not entirely satisfactory solution of the problem. On purely physicochemical grounds it is impossible to explain why a 10 per cent increase of vapor pressure should cause vaporization of water to increase 50 per cent, yet these are the magnitudes of the changes noted by these observers. Such a quantitative discrepancy suggests that the change of vaporization must be provoked by some attendant 
physiological reaction. This may possibly have an adaptive purpose. The insensible perspiration is peculiarly fitted for such a purpose since it is apparently able to eliminate water without appreciable amounts of solutes. How vaporization of water and heat loss by radiation can be simultaneously varied in opposite directions by such a physiological reaction it is hard to see, unless certain parts of the mechanism for the dissipation of heat are especially adapted to one or the other of the two functions. If the proportion of the heat lost by vaporization does fluctuate, it follows that the loss by radiation must vary in the opposite direction if the temperature of the body is to remain constant.

If the conflicting evidence presented above is reviewed, it seems quite possible to ascribe the disagreement to differences in the particular methods by which the volume of body fluids was changed in the various experiments. The pituitrin experiments seem particularly important because it has been clearly demonstrated that this hormone causes the retention of water without a proportional amount of salt. The simultaneous administration of pituitrin and water should, therefore, lower the osmotic pressure of the fluids of the body. This is well illustrated by experiments of Robert (32). He gave to a normal 19 year old male, who subsisted on a constant diet containing fixed quantities of fluid and salt, on separate days $1500 \mathrm{cc}$. of water with and without injections of pituitrin, pitressin or pitocin. After water alone there was a rapid diuresis, unaccompanied by any appreciable reduction of the osmotic pressure of the serum, measured either by cryoscopy or inorganic analysis. The extrarenal loss of weight during the 4 hours, which include the diuresis did not differ appreciably from that of the succeeding 4 hours. Pitocin, which modified the renal excretion of water but little, also failed to affect the insensible loss. On the other hand, after pituitrin and pitressin, but little of the water was eliminated in the urine during the first 4 hours, although the excretion of chloride was not greatly modified. Under these circumstances, during the first hours the osmotic pressure of the serum fell and simultaneously the insensible loss of water increased.

These experiments conform to the theory of Gilman and Barbour (33). In other cases, in- dubitable variations of insensible loss have been reported when, presumably at least, the osmotic pressure of the body fluids remained unchanged. In this category belongs Benedict's (34) study of a subject during a 30 day fast, the relevant data of which are presented in Table IV. In the first

TABLE IV

Comparison of energy expenditure measured with that estimated from insensible loss in Benedict's fasting man (34)

\begin{tabular}{|c|c|c|c|}
\hline Days inclusive & $\begin{array}{l}\text { Calories } \\
\text { measured }\end{array}$ & $\begin{array}{l}\text { Calories } \\
\text { calculated } \\
\text { from IW. }\end{array}$ & $\frac{(\mathrm{Na}+K) \text { urine }}{\mathrm{WB}^{*} \text { measured }}$ \\
\hline $\begin{array}{r}1 \text { to } 6 \ldots \ldots \\
7 \text { to } 12 \ldots \ldots \\
13 \text { to } 18 \ldots \ldots \\
19 \text { to } 24 \ldots \ldots \\
25 \text { to } 31 \ldots \ldots\end{array}$ & $\begin{array}{l}9999 \\
8745 \\
7950 \\
7508 \\
8808\end{array}$ & $\begin{array}{r}13150 \\
8780 \\
7190 \\
7150 \\
8800\end{array}$ & $\begin{array}{c}\text { m.Eq. } \\
\text { kgm. } \\
144 \\
155 \\
146 \\
137 \\
120\end{array}$ \\
\hline
\end{tabular}

* Water balance.

2 columns the heat production according to Benedict's own estimates is compared with that calculated from the insensible water loss. The latter was calculated from the body weight changes, urine weights and gas exchange, using Benedict's estimates of the food metabolized for the derivation of the gas exchange. During the first 6 days the heat production estimated from insensible water loss exceeds the measured heat production by more than 30 per cent. Subsequently the agreement between the two methods is reasonably satisfactory. Obviously during the initial diuresis provoked by the fast in this subject, loss of water by vaporization was also accelerated; the ratio of $(\mathrm{Na}+\mathrm{K})$ to water loss which is presented in the last column, nevertheless, gives no evidence that the osmotic pressure of the body fluids was reduced by excessive loss of salts during this period. In fact this ratio is higher during the second period when the value for metabolism calculated from insensible loss agrees almost exactly with Benedict's measurement.

In some of our cases (see Table III), it has already been noted that, though the metabolism must have been quite constant from day to day, the insensible loss was so variable that it could hardly be related quantitatively to energy production. No correlation can be discovered between 
the insensible loss and either the volume of body fluids or changes in this volume. For example, in Subject P. F., while the water balance is constantly strongly negative, as evidenced by the rapid loss of weight, the insensible loss in the last 2 periods greatly exceeds that of the earlier periods. That is, the insensible loss increased, although the volume of fluid in the body decreased. In Subject D. C., there is marked storage of water. The largest insensible loss occurs, however, in the first period when the volume of body fluids is smallest. In Subject J. M., retention of water was induced by giving large amounts of fluids, during the first 4 days without salt, during the last 4 days with salt. During the first 4 days, the base of the serum fell about 5 per cent while during the following 4 days the reverse is true. According to Gilman and Barbour, this should result in an increase of insensible loss above the normal during the first 4 days with a corresponding decrease during the last 4 days. Actually the average daily insensible loss of the last 4 days exceeds that of the first 4 days by 162 grams. Furthermore, although the average osmotic pressure of the body fluids during the beginning and end of the experiment must have been considerably higher than during the mid-portion, the average daily insensible loss of the first two days and last two days of the experiment falls short of that of the intervening 4 days by only 47 grams daily. In this experiment the changes in osmotic pressure of the body fluids are probably slowly progressive in contrast with the rapid changes induced by Gilman and Barbour, so that the two are not strictly comparable. The increase in volume of body fluids is approximately twice as great during the last 4 days of the experiment as it is during the first 4 days. The insensible loss is greater during the last 4 days, which is compatible with the findings of Manchester, Husted and McQuarrie. During the last 2 days, however, when the hydration of the body is greatest, the insensible loss is less than during the two preceding days, and is little greater than during the first 2 days when the subject was relatively greatly dehydrated. In Subject M. C., the volume and osmotic pressure of the body fluids were varied greatly by the administration of pituitrin and different amounts of salt. Extreme variability of insensible loss is noted, and although the greatest insensible loss occurs during the fifth period when the water retention is greatest, the next largest insensible loss occurs during the third period when there is a loss of over $2 \mathrm{kgm}$. of fluid from the body, and the smallest insensible loss occurs in the first period when there is an increase of over $1 \mathrm{kgm}$. in the volume of body fluid. With the concentration of base in the serum, and presumably, therefore, the osmotic pressure of the body fluids, decreasing constantly during the first 2 periods, the average daily insensible loss is smaller than it is in the subsequent 2 periods when the base of the serum rises greatly. In this case the variations in insensible loss can be related to changes in neither the volume nor the osmotic pressure of the body fluids.

These experiments not only indicate extreme variability of insensible perspiration, but also afford material to test the predictability of total metabolism from insensible perspiration. In the first 4 experiments, the subjects were maintained on the experimental diet for a considerable period before the experiments were conducted. The diets should have been quite adequate, and in all cases protein was stored. It seems improbable that the wastage of fat indicated by calculation of total metabolism from insensible perspiration in the first three experiments actually occurred under these circumstances. One can only conclude that an unusually large proportion of the heat produced was eliminated by vaporization. In the fourth experiment, the subject of which had nephritis, hypertension and heart disease of rheumatic origin, the insensible perspiration indicates approximate energy equilibrium for the entire study, which is reasonable. The essential difference between the first three experiments in which vaporization was excessive and this one in which the normal relationship between vaporization and total metabolism obtains is not clear. It may be added that in all of these experiments, as well as in similar additional experiments, in which ordinary mixed diets have been employed, it makes little difference whether metabolism is estimated from the measured insensible weight loss, as has been done in Table III, or from insensible water loss calculated indirectly according to the method of Newburgh, Wiley and Lashmet.

That Newburgh's experiments show remarkable agreement between actual and predicted me- 
tabolism over long periods of time can not be doubted. Under restricted conditions the insensible perspiration may yield valuable information concerning the energy metabolism, which can be obtained otherwise in no way short of direct calorimetry. It seems extremely doubtful, however, in view of the mass of experimental evidence to the contrary, that the method is applicable during conditions of changing hydration, or of value in the study of edema and diuresis, as has been asserted by Lashmet (35).

\section{SUMMARY AND CONCLUSIONS}

An attempt has been made to evaluate the errors attendant upon the determination of water balance by the commonly employed method described by Newburgh and his associates. This method attempts, by correcting changes of body weight for changes in the solid constituents of the body, to measure the actual exchange of water. These changes in solid constituents of the body, except under most unusual circumstances, do not exceed 100 grams daily, and usually lie well below this value. It follows that the combined errors of the determinations must be equally small if the method is to possess any practical value. Actually it has been shown that even the determination of dry weights of food and excreta may be subject to quite significant error. The assumption that carbohydrate fed and burned are equal is open to grave objection in experiments under varied conditions of nutrition, and the estimation of carbohydrate fed from food tables is probably subject to an error of at least $\pm \mathbf{5}$ per cent. Any error in the estimation of carbohydrate burned, however, will be balanced in part by a consequent opposite error in the estimation of fat burned in the formula

$$
F_{b}=\frac{I L-2.12 C_{b}-1.69 P_{b}}{3.78}
$$

Assuming that the amounts of carbohydrate and protein metabolized can be accurately estimated, the value for fat burned depends upon an accurate prediction of total energy production. For this purpose Newburgh has proposed to make use of the constancy of the relationship between water vaporized from the body and heat production. The error attendant upon such predictions has been shown to be great. The use of an average value for vaporization might result in any individual in a systematic unidirectional error of 10 per cent in the estimation of metabolism. At a metabolism of 3000 calories per day, this would introduce an error of $300 / 9.3=32.4$ grams per day into the estimation of fat burned, and thus of water exchange. With the greater variability in this relationship noted in experiments on diseased subjects, a proportionately greater error may occur. The most extreme variability has been observed in experiments in which the volume of fluid in the body is greatly altered, the very experiments which are most interesting from the standpoint of water exchange. It has also been suggested that, contrary to the statement of Newburgh, Wiley and Lashmet, when work is performed, the difference between total energy production and heat elimination need not be insignificant. Furthermore, at least when work is productive of sensible perspiration, the proportion of heat eliminated by vaporization increases greatly over the basal value. The magnitude of the errors incurred in the determination of water exchange by this method are, except in extremely limited conditions, great enough to make it quite impracticable.

At best the method affords no knowledge concerning the allocation of these fluids within the body. It does not distinguish between changes in the volume of fluid in the cells, interstitial fluids or gastro-intestinal tract although changes in these various compartments of the body fluids must have widely differing significance for the body economy.

\section{BIBLIOGRAPHY}

1. Newburgh, L. H., Johnston, M. W., and FalconLesses, M., Measurement of total water exchange. J. Clin. Invest., 1929-30, 8, 161.

2. Peters, J. P., Kydd, D. M., and Lavietes, P. H., A note on the calculation of water exchange. $J$. Clin. Invest., 1933, 12, 689.

3. Atwater, W. O., and Bryant, A. P., The chemical composition of American food materials. U. S. Dept. of Agriculture Bull., 1906, No. 28.

4. Soderstrom, G. F., and DuBois, E. F., Clinical calorimetry. XXV. The water elimination through skin and respiratory passages in health and disease. Arch. Int. Med., 1917, 19, 931.

5. Levine, S. Z., and Wilson, J. R., Respiratory metabolism in infancy and childhood. VII. Elimination of water through the skin and respiratory passages of infants. Am. J. Dis. Child., 1928, 35, 54. 
6. Heller, H., and Schwarz, A., Extrarenale Wasserausscheidung und Stoffwechsel. II. Die Verhältnisse bei Umsatzsteigerungen. Ztschr. f. d. ges. exper. Med., 1930, 71, 416.

7. Benedict, F. G., and Root, H. F., Insensible perspiration: Its relation to human physiology and pathology. Arch. Int. Med., 1926, 38, 1.

8. Jores, A., Perspiratio insensibilis. Ztschr. f. d. ges. exper. Med., 1930, 71, 170.

9. Heller, H., Studien über Perspiratio insensibilis. II. Uber den Einfluss der atmosphärischen Factoren auf die Perspiratio insensibilis bei mittleren Lufttemperaturen und mittlerer relativer Luftfeuchtigkeit. Ztschr. f. d. ges. exper. Med., 1932, 81, 698.

10. Levine, S. Z., and Marples, E., The insensible perspiration in infancy and childhood. III. Basal metabolism and basal insensible perspiration of the normal infant; a statistical study of reliability and of correlation. Am. J. Dis. Child., 1930, 40, 269.

11. Johnston, M. W., and Newburgh, L. H., The determination of the total heat eliminated by the human being. J. Clin. Invest., 1930, 8, 147.

12. Newburgh, L. H., Wiley, F. H., and Lashmet, F. H., A method for the determination of heat production over long periods of time. J. Clin. Invest., 1931, 10, 703.

13. Newburgh, L. H., Personal communication to Dr. J. P. Peters.

14. Atwater, W. O., and Benedict, F. G., Experiments on the metabolism of matter and energy in the human body. U. S. Dept. of Agriculture Bull., 1903, No. 136.

15. Benedict, F. G., and Carpenter, T. M., The metabolism and energy transformations of healthy man during rest. Carnegie Institution of Washington, 1910, Publication No. 126.

16. Christie, R. V., and Loomis, A. L., The pressure of aqueous vapor in the alveolar air. J. Physiol., 1932, 77, 35.

17. Benedict, F. G., and Benedict, C. G., Perspiratio insensibilis; Ihr Wesen und ihre Ursachen. Biochem. Ztschr., 1927, 186, 278.

18. Bazett, H. C., and McGlone, B., Temperature gradients in the tissues in man. Am. J. Physiol., 1927, 82,415 .

19. Loewy, A., and Wechselmann, W., Zur Physiologie und Pathologie der Wasserwechsels und der Wärmeregulation seitens des Hautorgans. Virchow's Arch. f. Path. Anat., 1911, 206, 79.

20. Richardson, H. B., Clinical calorimetry. XL. The effect of the absence of sweat glands on the elimination of water from the skin and lungs. J. Biol. Chem., 1926, 67, 397.
21. Hancock, W., Whitehouse, A. G. R., and Haldane, $J$. S., The loss of water and salt through the skin and the corresponding physiological adjustments. Proc. Roy. Soc., London, s. B, 1929, 105, 43.

22. Vasti, A., The insensible water loss through the skin. Am. J. Physiol., 1932, 102, 60.

23. Coleman, W., and DuBois, E. F., Clinical calorimetry. VII. Calorimetric observations on the metabolism of typhoid patients with and without food. Arch. Int. Med., 1915, 15, 887.

24. Barr, D. P., and DuBois, E. F., Clinical calorimetry. XXVIII. The metabolism in malarial fever. Arch. Int. Med., 1918, 21, 627.

25. Barr, D. P., Cecil, R. L., and DuBois, E. F., Clinical calorimetry. XXXII. Temperature regulation after the intravenous injection of proteose and typhoid vaccine. Arch. Int. Med., 1922, 29, 608.

26. Coleman, W., Barr, D. P., and DuBois, E. F., Clinical calorimetry. XXX. Metabolism in erysipelas. Arch. Int. Med., 1922, 29, 567.

27. Manchester, R. C., Husted, C., and McQuarrie, I., Influence of the state of hydration of the body on the insensible loss of weight in children. J. Nutrition, 1931, 4, 39.

28. Newburgh, L. H., and Johnston, M. W., Relation between dehydration and the insensible loss of water. J. Nutrition, 1934, 7, 107.

29. Levine, S. Z., Wilson, J. R., and Kelly, M., The insensible perspiration in infancy and in childhood. I. Its constancy in infants under standard conditions and the effect of various physiological factors. Am. J. Dis. Child., 1929, 37, 791.

30. Levine, S. Z., and Wyatt, T. C., Insensible perspiration in infancy and in childhood. IV. Basal measurements in dehydrated infants. Am. J. Dis. Child., 1932, 44, 732.

31. Jores, A., Perspiratio insensibilis. II. Uber die Beziehungen zwischen renaler und extrarenaler Wasserausscheidung. Ztschr. f. d. ges. exper. Med., 1930, 74, 757.

32. Robert, F., Uber die Einwirkung von Hypophysin und seinen Fractionen auf den Wasser-Salzstoffwechsel. Arch. f. exper. path. u. Pharmakol., 1932, $164,367$.

33. Gilman, A., and Barbour, H. G., The relation between blood osmotic pressure and insensible weight loss. Am. J. Physiol., 1933, 104, 392.

34. Benedict, F. G., A study of prolonged fasting. Carnegie Institution of Washington, 1915, Publication No. 203.

35. Lashmet, F. H., A new method of studying edema. J. Michigan Med. Soc., 1932, 31, 114. 